\title{
Mais ou Menos Morto: Explorações sobre a Formação do Conceito de Morte em Crianças
}

\author{
More or Less Dead: Explorations about the Construction \\ of the Concept of Death in Children
}

\author{
Maira Monteiro Roazzi ${ }^{*}{ }^{a}$, Maria da Graça Bompastor Borges Dias ${ }^{b}, \&$ Antonio Roazzi ${ }^{b}$ \\ ${ }^{a}$ University of Pittsburgh, Pitsburg, Estados Unidos \& ${ }^{b}$ Universidade Federal de Pernambuco, Recife, Brasil
}

\begin{abstract}
Resumo
O objetivo da presente pesquisa é investigar quando concepções religioso-metafísicas e secular-biológicas surgem no desenvolvimento do conceito de morte. Foram entrevistadas noventa e duas crianças com idades entre 6-8 e 10-12 anos, estudantes de escolas públicas e privadas localizadas na cidade do Recife, Brasil. Foram apresentadas duas narrativas aos participantes descrevendo a morte de uma avó ou avô, para em seguida solicitar que julgassem se certos processos corporais e mentais deixavam ou não de funcionar após a morte. Os resultados indicam que crianças de ambos os grupos de idade apresentaram uma forte visão secular-biológica da morte. As crianças também fizeram distinções entre corpo e mente, emitindo justificativas de cunho secular-biológico para funções corporais e justificativas de cunho religiosometafísico para funções mentais.
\end{abstract}

Palavras-chave: Conceito de morte; Secular-biológico; Religioso-metafísico.

\begin{abstract}
The objective of the present project lies on investigating when religious/metaphysical and secular/biological conceptions emerge in the development of a concept of death. A total of 92 children of 6-8 and 1012 years old, from public and private schools, all from the city of Recife in Brazil were interviewed. Participants were presented to two narratives depicting the death of a grandparent and were further asked to judge if certain bodily and metal functioning cease or not after death. Findings indicate that children from both group ages hold an overall strong secular-biological view of death. In addition, children made distinctions between body and mind, giving secular/biological explanations to body functioning and religious/metaphysical ones to mental functioning.

Keywords: Concept of death; Secular-biological; Religious-metaphysical.
\end{abstract}

O Conceito de Morte é uma representação, imagem ou idéia acerca do que vem a ser esse fenômeno. O desenvolvimento de tal conceito pode suscitar diversas interpretações por pessoas em diferentes contextos, fase de vida, cultura dominante ou religião. Em uma perspectiva secular-biológica, a morte é concebida como um ponto terminal, quando a máquina corporal para de trabalhar. Ao adotar este ponto de vista, acredita-se que a vida de qualquer pessoa acaba irreversivelmente e completamente com o advento da morte (Brent, Speece, Lin, Dong, \& Yang, 1996; Harris \& Gimenez, 2005). A segunda perspectiva exemplifica uma visão comum a inúmeras religiões no mundo, em que a morte é considerada uma metamorfose - o começo de outro tipo de vida que não obedece somente a processos biológicos. Neste ponto de vista, ela é vista como uma transição, não como um fim

\footnotetext{
Endereço para correspondência: University of Pittsburgh, Department of Psychology, 3412 Sennott Square, 210 S. Bouquet St., Pittsburgh, PA, USA, 15260. E-mail:mmr41@pitt.edu
}

(Astuti \& Harris, 2008; Bering, 2006; Harris \& Gimenez, 2005). Este trabalho pretende conhecer como crianças conceituam a morte, e até que ponto elas consideram estas duas alternativas como compatíveis ou não.

Partindo-se de uma visão teórica alicerçada em pressupostos do desenvolvimento cognitivo postulados pela teoria da teoria ${ }^{1}$, acredita-se que crianças ao explorar o mundo, são como pequenos cientistas, capazes de construir teorias populares (folk), intuitivas e ingênuas. Estas teorias são guiadas e limitadas por domínios específicos do saber, tais como o domínio da física, da biologia e da psicologia (Miller, 2002; Wellman, 1990). O conhecimento dentro de cada domínio obedece a diferentes mecanismos explanatório-intuitivos. Estes mecanismos são compostos por teorias intuitivas, sendo guiados e gerados por uma estrutura causal-explanatória, que por sua vez ocorrem dentro de um contexto cultural (Wellman \& Johnson, 2008). É possível assim, que crianças pos-

${ }^{1}$ Tradução do termo em inglês theory theory. 
suam diferentes teorias explanatório-intuitivas para explicar a morte, podendo adotar tanto uma perspectiva biológica/secular, guiada pelo domínio da biologia, quanto uma perspectiva metafísico-religiosa, guiada pelo domínio da psicologia.

Na última década, estudos acerca do desenvolvimento do conceito de morte têm focado primordialmente no entendimento dos limites biológicos impostos pela morte. Conhecimento este, guiado por mecanismos explanatório-intuitivos do domínio da biologia (Inagaki \& Hatano, 2002). Mais especificamente, tem se estudado a compreensão de quatro aspectos da biologia do processo: (a) Universalidade: a compreensão que todos os seres vivos devem morrer um dia; (b) Irreversibilidade: o fato de que uma vez morto, não pode voltar à vida; (c) Cessação da vida corporal: a compreensão que a morte envolve o fim de todas as funções corporais e dos órgãos; e (d) Causalidade: a noção de que é precisamente a cessação das funções corporais que causa a morte (Brent et al., 1996; Torres, 1979).

Os estudos desenvolvidos nesta área apontam que crianças jovens adotam um ponto de vista secular-biológico, concebendo a morte como o fim da vida (Brent et al., 1996; Nunes, Carraro, De Jou, \& Sperb, 1998; Torres, 1979; Wenestram \& Wass, 1987). Já adolescentes e adultos incorporam elementos religiosos em sua concepção de morte (Brent et al., 1996). Estes resultados parecem apontar para um processo de transição em suas concepções de morte, os quais nos levam aos seguintes questionamentos: Como estas perspectivas são adquiridas? Elas se alternam ou coexistem? De que maneira diferentes visões religiosas influenciam na construção deste conceito? Existe um padrão universal na construção de tal conceito, comum a diversas culturas?

Harris e Gimenez (2005) buscaram responder alguns dos questionamentos supracitados, examinando em que extensão crianças de 7 a 11 anos demonstram adotar essas duas concepções (secular-biológica e religioso-metafísica) de morte. Quando questionadas sobre a continuação de funções corporais dentro de um contexto narrativo secular, elas geralmente insistiam que o funcionamento de tais processos cessava após a morte. Por outro lado, quando questionadas quanto ao funcionamento de certos processos mentais dentro de um contexto narrativo religioso, elas frequentemente afirmavam que tais processos continuavam a funcionar após a morte. Este conceito duplo da morte (fim biológico ou transformação metafísica) mostrou-se mais evidente entre as crianças de 11 anos.

Argumentou-se inicialmente que o desenvolvimento do conceito de morte é guiado por mecanismos intuitivoexplanatórios, e que tal processo está inserido em um contexto cultural. Diante disto, Astuti e Harris (2008) realizaram um estudo similar, em que crianças de 7 a 17 anos foram entrevistadas sobre a morte. Todos os participantes viviam em uma região rural de Madagascar, em uma comunidade onde as crenças e práticas sobre ances- trais eram disseminadas. Participantes foram questionados se certos processos mentais e corporais continuavam a funcionar após a morte. A morte em questão foi apresentada em dois contextos: biológico e religioso. Os participantes que tinham em média 8 anos afirmaram que a morte provocava o fim da maior parte das funções corporais e mentais. No entanto, quando apresentados em especial à narrativa religiosa, os participantes afirmavam que certos processos mentais continuavam a funcionar após a morte. Esta alegação crescia à medida que aumentava a idade dos participantes.

Os resultados obtidos por Astuti e Harris (2008), corroboram os estudos de Brent et al. (1996), Harris e Gimenez (2005) e Wenestram e Wass (1987), em que crianças demonstram conceber a morte recrutando intuições do domínio da biologia e da psicologia, atribuindo um fim biológico ao corpo e assumindo uma continuação de processos mentais. Evidencia-se ainda que estas construções teóricas variam com a idade dos participantes. Por fim, estudos realizados em contextos culturais diversos (USA, Espanha e Madagascar) apontam para um mesmo padrão de construção do conceito de morte (Astuti \& Harris, 2008; Brent et al., 1996; Harris \& Gimenez, 2005).

Os estudos desenvolvidos no Brasil, realizados dentro de uma tradição cognitiva, focalizam predominantemente um entendimento biológico da morte (Nunes et al., 1998; Torres, 1979). O presente trabalho se propõe verificar o estudo de Harris e Gimenez (2005) com uma amostra de crianças recifenses, uma vez que ainda são poucas as pesquisas no país que investigam o duplo entendimento da morte (religioso e secular).

O estudo, assim, possui quatro objetivos principais. Primeiramente, verificar quando concepções religiosometafísicas e secular-biológicas surgem no desenvolvimento conceitual da morte em crianças. Tomando-se por base os estudos apresentados acima, espera-se que crianças mais jovens apresentem maior ênfase em um entendimento biológico, enquanto que as mais velhas passem a incorporar elementos religiosos e/ou metafísicos em seu entendimento. Em segundo lugar, objetivamos uma comparação dos resultados obtidos por Harris e Gimenez (2005) com os obtidos na presente investigação. O intuito principal foi de verificar diferenças e/ou semelhanças no surgimento de concepções religioso-metafísicas e secular-biológicas no desenvolvimento conceitual da morte em crianças de ambas as culturas.

Levando-se em conta pressupostos teóricos da teoria da teoria, assim como os estudos revisados acima, partimos do pressuposto de que as crianças apresentam aspectos das duas perspectivas: secular-biológica e religioso-metafísica. Incluiu-se então como terceiro objetivo, verificar se as crianças consideram as duas concepções incompatíveis, ou, alternativamente diferentes, mas compatíveis. Se as crianças acreditam na incompatibilidade das duas concepções, é de se esperar que não expressem ambas. Assim, se são apresentados às crianças questionamentos 
acerca da morte em um contexto narrativo do tipo religioso ou secular, é de se esperar que respondam de forma relativamente consistente para ambos. Afirmando em cada contexto, que a maioria - se não todos os processos - termina com a morte e produzindo justificativas do tipo secular-biológico, ou alternativamente, afirmando que a maioria - se não todos os processos - continuam depois da morte e produzindo justificativas de cunho religioso. Por outro lado, se as crianças consideram estes dois entendimentos de morte como diferentes, porém compatíveis, esperar-se-ia um deslocamento de uma concepção a outra, dependendo do contexto narrativo.

$\mathrm{O}$ quarto objetivo visa explorar se as crianças concebem uma pessoa como um ser inteiro indivisível, ao analisar perspectivas conceituais distintas acerca da morte (i.e mente e corpo), mas, no entanto, relacionadas (i.e. olho e visão). Por exemplo, ao questioná-las sobre processos corporais (se os olhos ou cérebro ainda funcionam) ou sobre processos mentais concomitantes (se a visão ou o cérebro funcionam), elas devem, portanto, produzir respostas consistentes. Como por exemplo, afirmando que ambas a visão e a função dos olhos funcionam. Caso sejam suscetíveis a pensamentos dualísticos, em que a natureza e função do corpo são concebidas como radicalmente diferente da mente (Wellman \& Johnson, 2008), poderiam afirmar, por exemplo, que apesar de se ter perdido os sinais vitais (processos corporais) o processo mental continuaria ativo. Elas ainda podem produzir justificativas diferentes para casos díspares, ou seja, explicações biológicas para a cessação de processos corporais e explicações religiosas para a continuação de processos mentais. Levou-se em conta, no presente estudo, a faixa etária e classe social das crianças, a fim de obter um panorama do processo de construção do conceito de morte, como também verificar se as duas variáveis determinam o curso tomado neste processo cognitivo.

\section{Método}

\section{Participantes}

Foram entrevistadas 92 crianças, subdivididas em dois grupos, sendo 46 com idade entre 6 a 8 anos (média de 6 anos e 3 meses - 8 anos e 11 meses, idade média 7,3 - DP 0,58 ) e 46 entre 10 a 12 anos (média de 10 anos e 1 mês - 12 anos, idade média 10,8 - DP 0,45). Metade das crianças de cada grupo frequentava escolas públicas ( $n=49,24$ de 6-8 anos e 25 de 10-12 anos) e a outra metade era de escolas particulares $(n=43,21$ de $6-8$ anos e 22 de 10-12 anos). Todas as escolas situadas na Região Metropolitana de Recife (RMR) e não religiosas.

\section{Material e Procedimentos}

Foram apresentadas duas narrativas diferentes sobre a morte de uma pessoa idosa (um avô e uma avó) - uma narrativa religiosa e uma narrativa secular. Na narrativa com sugestão religiosa, foram incluídos elementos tais como o padre, e a pessoa falecida estando com Deus (Anexo A). Na narrativa secular, nenhuma sugestão religiosa foi incluída, mas sim um médico explicando a morte da avó para a família (Anexo A).

Após a apresentação de cada narrativa, foram efetuadas doze perguntas visando explorar concepções sobre as funções presentes nas pessoas, mas que cessam após a morte. Metade das perguntas fazia referência às funções do corpo, mais especificamente sobre alguns órgãos e o corpo como um todo. Desta forma, as crianças foram questionadas sobre: olhos, coração, cérebro, orelhas, boca, e corpo em si. A outra metade remetia ao funcionamento da mente. Assim, as crianças foram questionadas sobre: emoção e sentimento, mente, ato de ver, pensar, ouvir e falar.

As perguntas que foram feitas após a narrativa secular foram do seguinte tipo: "agora que o avô de Alfredo morreu, seus olhos ainda funcionam?" ou "agora que o avô de Alfredo morreu, pode ver alguma coisa?”. E as perguntas feitas após a narrativa religiosa, foram do seguinte tipo: "agora que a avó de Clara Nina está com Deus, seus olhos ainda funcionam?". Após cada uma das duas questões mais gerais, isto é, as questões relativas ao corpo e a mente, foi solicitado que as crianças justificassem as suas respostas. Mais especificamente, perguntou-se às crianças "Por que o corpo/mente, dele/ dela, ainda está/não está, funcionando mais?".

$\mathrm{O}$ mesmo conjunto de questões foi apresentado para cada uma das duas narrativas de forma que as crianças responderam às mesmas perguntas, duas vezes. Três das seis questões relativas ao corpo foram formuladas em um formato negativo, apresentando a criança que o órgão (olho, orelha...) ou função (ver, ouvir...) não funcionava mais. Desta maneira, a pergunta foi formulada "agora que a avó de Clara Nina está com Deus, seu olho não funciona mais?" levando a criança a emitir uma resposta como, por exemplo, "sim". As outras três questões foram formuladas em um formato positivo, apresentando à criança que o órgão (olho, orelha...) ou função (ver, ouvir...) funciona. Desta maneira, a pergunta foi formulada "agora que a avó de Clara Nina está com Deus, seu olho funciona?" levando a criança a emitir uma resposta como, por exemplo, "não", inversamente a emitida no formato anterior, mas contendo o mesmo significado. De forma similar, três das seis questões relativas à mente foram formuladas no formato "sim". As outras três no formato "não".

Foram elaboradas duas versões alternativas do questionário $\mathrm{A}$ e $\mathrm{B}$ de tal forma que qualquer questão foi colocada tanto no formato de resposta positiva como negativa. Por exemplo, na versão $\mathrm{B}$, a questão relativa à visão é "agora que a avó de Clara Nina está com Deus, ela pode ver?", na versão A, a questão é "agora que a avó de Clara Nina está com Deus, ela parou de ver?". Metade dos participantes respondeu ao questionário na versão A e a outra metade na versão B. O primeiro grupo 
iniciou com a narrativa religiosa e em seguida a narrativa secular. Para o segundo grupo a ordem da apresentação das narrativas foi o inverso (secular primeira, seguida pela religiosa).

Enfim, para cada versão e tipo de narrativa, enquanto metade dos participantes respondeu inicialmente as seis respostas relativas ao corpo e, em seguida, as seis questões relativas à mente, a outra metade dos participantes respondeu em ordem invertida. A ordem de cinco das seis questões foi aleatória (randomizada), tanto para o conjunto de questões relativas ao corpo, como para o conjunto de questões relativas à mente. As questões sobre o funcionamento da mente e do corpo como um todo foram sempre colocadas no final das seis questões, visto que após este tipo de pergunta solicitava-se sempre uma justificativa.

\section{Resultados}

Os resultados serão apresentados em duas sessões. Num primeiro momento serão descritos os julgamentos quanto à cessação ou continuação de processos mentais e corporais após a morte. Em seguida, serão apresentadas as justificativas para tais julgamentos. Num segundo momento serão comparados os resultados deste estudo com os dados obtidos por Harris e Gimenez (2005) na Espanha.

\section{Análise dos Julgamentos}

As respostas das crianças às perguntas quanto aos processos corporais e mentais foram codificadas binariamente, como julgamentos no formato "funciona" ou "não funciona".

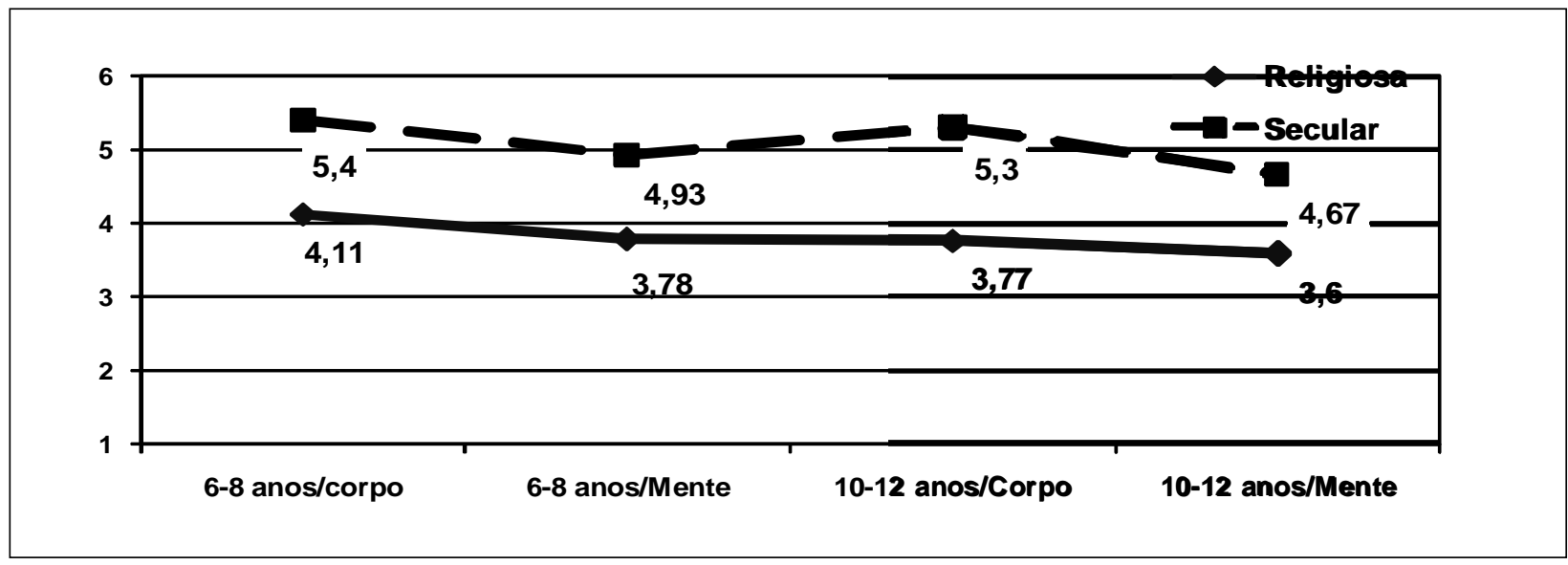

Figura 1. Média das respostas do tipo "não funciona” em função da Idade, Narrativa (Secular versus Religiosa) e Tipo de processo (Corpo versus Mente)

Estes resultados sugerem as seguintes tendências: Primeiro, as respostas do tipo "não funciona" se apresentaram da mesma forma entre os dois grupos de idade. Segundo, o padrão das respostas varia marcadamente dependendo do tipo de narrativa. As respostas do tipo "não funciona" foram menos frequentes no contexto religioso do que no contexto secular. Finalmente, respostas do tipo "não funciona" foram menos frequentes em questões sobre a mente do que em questões sobre o corpo.

Devido a homogeneidade das variáveis, foi realizada uma ANOVA mista de Idade x Narrativa x Tipo de Processo, verificando as suposições acima apontadas, por meio dos efeitos principais de tipo de processo $(F(1,89)$ $=5,68, p=0,019$; média Corpo 4,60 vs. média Mente $4,21)$ e narrativa $(F(1,89)=42,42, p=0,001$; média Religiosa 3,77 vs. média Secular 4,21). O efeito principal de idade não foi significativo como também não houve efeitos interativos significativos.

\section{Análise das Justificativas}

Em seguida, foram examinadas as justificativas das crianças ao funcionamento ou não da mente e do corpo após a morte. As respostas foram alocadas nas seguintes categorias:

Ausência de Movimento: as justificativas se referiram à ausência de movimento ou ação. "Porque ele morreu $e$ não se mexe mais". Médico-Biológico: respostas fazem referência a órgãos internos específicos e/ou substâncias. "O coração parou de funcionar, ele morreu”. Fim da Vida: explicações que trazem a morte como o fim da vida ou o fim das funções (mentais/corporais). "Porque quando morre, é o fim da vida, ela acabou com a morte". Decomposição: justificativas que se referem à decomposição do corpo após a morte. "Ele morreu e o corpo dele vai apodrecer". Morto/ Enterrado: as respostas referem-se à morte e enterro sem maiores elaborações. "Porque ele morreu", "Ela tá morta", "ele está morto e enterrado". Deus/ Céu: respostas que afirmam que o fato de estar com Deus ou no céu possibilita o corpo ou a mente a manter suas funções. "Ele está com Deus e lá ele fala com os anjos". Partes: explicações que afirmam que existe uma parte da mente ou do corpo - ou alguma entidade especial, tal como a alma, espírito ou a consciência - que continua a funcionar ou que permanece 
mesmo com o cessar de outras funções do corpo ou da mente. "A alma dele ainda funciona" "o espírito dele continua a existir". Não informativas: Resposta que não classificava ou do tipo, "eu não sei".

As crianças apresentaram quatro justificativas, duas para a mente e duas para o corpo em ambos os contextos, religioso e secular. Cada justificativa foi examinada independentemente e alocada para uma das categorias acima citadas. Quando pertinente, a justificativa era alocada em duas categorias. Por exemplo, alguns participantes afirmavam que a personagem estava morta e enterrada, mas que sua alma ia para o céu. Neste caso a justificativa era alocada para as categorias "Morto e Enterrado" e "Deus/Céu”.

As justificativas foram codificadas por dois pesquisadores independentemente chegando a um acordo em $83 \%$ das respostas, para o restante foi chamada um terceiro pesquisador (não ciente das hipóteses do estudo) a fim de se alcançar um acordo em relação. Em seguida, estas justificativas e suas categorias foram re-classificadas em dois grandes grupos: um deles no qual as respostas eram religioso-metafísicas e outro em que as respostas eram secular-biológicas. Os critérios para tal tinham como intuito verificar a essência de cada uma das categorias (metafísico-religiosa ou secular-biológica). Desta maneira, as categorias ausência de movimento, fim da vida, médico - biológico, decomposição e morto/enterrado foram re-classificadas para o grupo onde as respostas eram de essência secular-biológica. As categorias Deus/ céu e partes foram re-classificadas para o grupo onde as respostas eram de essência metafísico-religiosa.

A Figura 2 apresenta a média das justificativas secularbiológicas em função da idade, narrativa (secular versus religiosa) e tipo de processo (corpo versus mente).

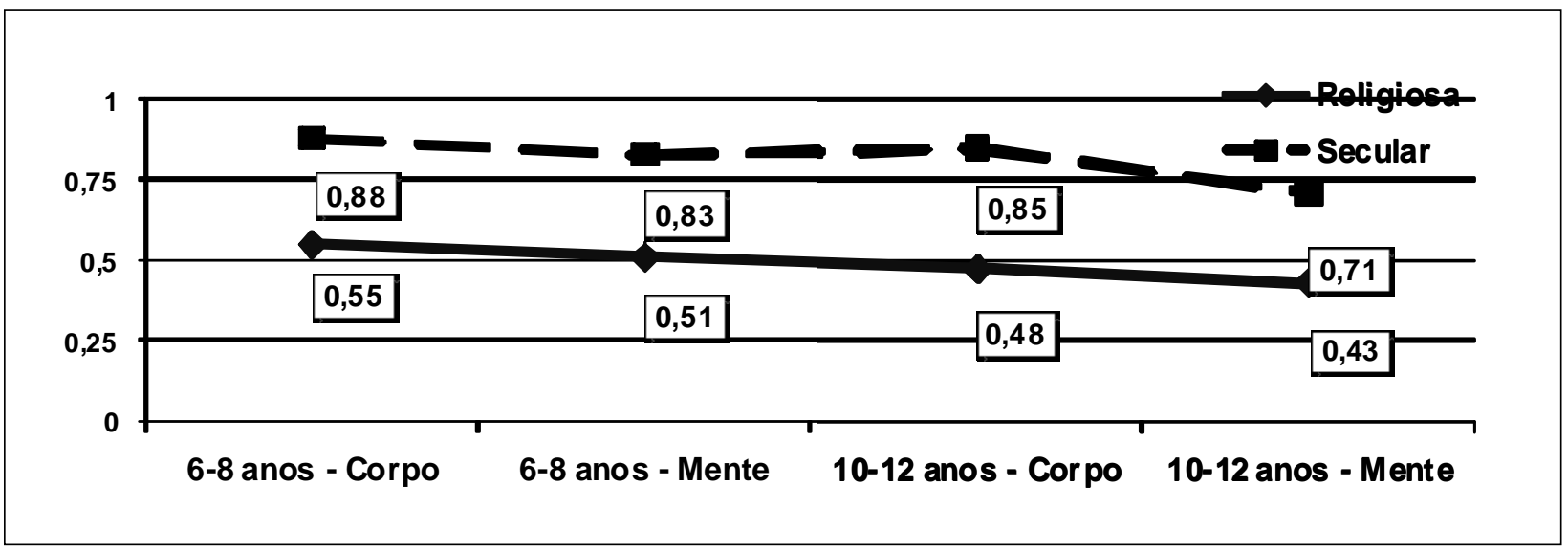

Figura 2. Média das justificativas biológicas em função da Idade, Narrativa (Secular versus Religiosa) e Tipo de Processo (Corpo versus Mente)

Observa-se, primeiramente, que não houve diferença entre as idades. Apresentando assim, tanto as crianças mais novas quanto as mais velhas, o mesmo padrão de resposta. Porém, é evidente uma leve tendência nas crianças mais velhas de emitirem julgamentos metafísicos. Em segundo lugar, observa-se um maior número de justificativas secular-biológicas em um contexto secular, enquanto que há um maior número de justificativas metafísico-religiosas no contexto religioso. Em terceiro lugar, nota-se um maior número de justificativas secular-biológicas para os processos corporais do que para os processos mentais.

Considerando a não normalidade da distribuição das variáveis, optou-se por analisar estes resultados por meio de análises não-paramétricas. A Tabela 1 apresenta comparações entre as faixas etárias (6 a 8 e 10 a 12 anos) para cada condição por meio do teste de Kruskal-Wallis. Os resultados indicam não haver diferenças significativas entre as duas faixas etárias para as condições religiosa-corpo $\left(\chi^{2}=0,44\right.$, g.l. $\left.2, p=0,509\right)$, religiosa-mente $\left(\chi^{2}=0,54\right.$, g.l. $\left.2, p=0,461\right)$, secular-corpo $\left(\chi^{2}=0,10\right.$, g.l. $2, p=0,748)$ e secular-mente $\left(\chi^{2}=1,81\right.$, g.l. $\left.2, p=0,178\right)$.

Comparações entre as várias condições por cada faixa etária (6-8 e 10-12 anos) por meio do teste de Friedman mostraram diferenças significativas em cada uma das duas faixas etárias (6-8 anos: $\chi^{2}=23,7$, g.l. $3, p=0,001$; 10-12 anos: $\chi^{2}=30,92$, g.1. $\left.3, p=0,001\right)$. Apontando uma variação na maneira como cada grupo responde a cada bloco de perguntas.

Análises a posteriori através de cada condição isoladamente com cada uma das outras duas condições foram computadas por meio do teste de Wilcoxon. No grupo de crianças de 6-8 anos de idade constatam-se diferenças significativas entre religiosa-corpo/secular-corpo $(z=-$ $3,05, p=0,002)$, religiosa-corpo/secular-mente $(z=-2,58$, $p=0,011)$, religiosa-mente/secular-corpo $(z=-3,50$, $p=0,001)$ e religiosa-mente/secular-mente $(z=-2,84$, $p=0,005)$. No grupo de crianças de 10-12 anos de idade as análises indicam haver diferenças significativas entre religiosa-corpo/secular-corpo $(z=-4,12, p=0,001)$, reli- 
Tabela 1

Médias, Desvio Padrão e Análises Não-paramétricas (Kruskal-Wallis e Friedman) das Justificativas Biológicas em Função da Idade (6-8 e 10-12 anos), Narrativa (Secular versus Religiosa) e Tipo de Processo (Corpo versus Mente)

\begin{tabular}{lcccccc}
\hline Condições: & \multicolumn{2}{c}{$6-8$ anos } & \multicolumn{2}{c}{$10-12$ anos } & \multicolumn{2}{c}{ Kruskal-Wallis } \\
\cline { 2 - 7 } Narrativas e Processos & Média & $D P$ & Média & $D P$ & $\chi^{2}$ (g.l. 2) & $P$ \\
\hline Religiosa - Corpo (RC) & 0,55 & 0,504 & 0,48 & 0,505 & 0,44 & 0,509 \\
Religiosa - Mente (RM) & 0,51 & 0,506 & 0,43 & 0,501 & 0,54 & 0,461 \\
Secular - Corpo (SC) & 0,88 & 0,335 & 0,85 & 0,360 & 0,10 & 0,748 \\
Secular - Mente (SM) & 0,83 & 0,377 & 0,71 & 0,458 & 1,81 & 0,178 \\
\hline Friedman (g.l. =3) & $\chi^{2}=23,7$ & $p=0,001$ & $\chi^{2}=30,92$ & $p=0,001$ & & \\
\hline
\end{tabular}

giosa-corpo/secular-mente $(z=-2,67, p=0,008)$, religiosamente/secular-corpo $(z=-4,35, p=0,001)$, religiosamente/secular-mente $(z=-2,82, p=0,005)$ e religiosamente/ secular-corpo $(z=-2,33, p=0,020)$. Os resultados apontam que os participantes de ambas as idades respondem de maneira diferenciada, dependendo do contexto na qual a narrativa é apresentada (religiosa ou secular) e dependendo do tipo de processo ao qual a pergunta se refere (corpo ou mente).

\section{Análise Conjunta dos Julgamentos e das Justificativas}

Os resultados apresentados analisaram separadamente os julgamentos dos participantes quanto a uma série de questões sobre o funcionamento do corpo e da mente, e em seguida as justificativas produzidas após os julgamentos. É importante relacionar estes dois tipos de respostas sem perder a especificidade dos detalhes produzidos pelos respondentes.

Nesta análise, os julgamentos dos participantes nas seis questões que compunham cada condição, foram agregados em grupos para se obter desta forma um único escore representando cada condição. Considerando a distribuição não normal das respostas produzidas nas justificativas e a necessidade de estabelecer relações mais complexas considerando o grande número de variáveis envolvidas, optou-se por realizar análises multidimensionais não paramétricas.

Assim, em um primeiro momento, para se determinar o grau de inter-correlação das 24 questões conforme julgamento emitido pelas crianças, realizou-se uma análise da estrutura de similaridade ([SSA], Similarity Structure Analysis). O SSA é um subgrupo de um conjunto de análises não métricas de dados, denominadas análises de estatísticas multidimensionais ([MDS], Multidimensional Scaling), a partir do qual se representa a estrutura de dados em uma projeção espacial. A representação da relação estatística de correlação dos dados neste método multidimensional mostra uma estrutura de correlações entre todos os elementos do sistema agregados segundo regiões de contiguidade (Young, 1987). Esta análise constrói uma representação geométrica dos dados em um espaço euclidiano. Assim, as variáveis são representadas graficamente como pontos em um espaço. Os pontos representando variáveis neste espaço são localizados de tal maneira que, quanto maior a correlação entre duas variáveis, menor a distância entre os mesmos e mais próximos se encontram na projeção (Guttman, 1968; Roazzi, 1995; Young, 1987).

Após ser analisada a projeção da estrutura relacional dos 24 julgamentos (variáveis conteúdo), foi desenvolvida uma análise complementar utilizando o "método de variáveis externas como pontos" (Cohen \& Amar, 1999, 2002; Roazzi \& Dias, 2001), para estabelecer a correlação existente entre a estrutura dos julgamentos e as variáveis não-conteúdo (background). Esta última análise permite associar as justificativas produzidas por cada condição (Secular-biológica e Religioso-metafísica) conforme descrito na seção anterior sobre os julgamentos, com a estrutura das respostas resultante na projeção sem alterar sua estrutura original. Foi inserida na análise SSA a variável idade como variável externa de maneira dicotômica em dois grupos: 6-8 anos e 10-12 anos.

Para gerar um único mapa integrado capaz de representar todos os dados (variáveis de conteúdo e externas) foi criada uma série de variáveis "dummy" a partir da variável justificativa e idade. A Figura 3 apresenta uma projeção SSA (coordenada $1 \times 2$ de 3D), relativa à análise dos 24 julgamentos (0 "funciona", 1 "não funciona") quanto ao funcionamento dos processos mentais (M) e corporais (C) em função do tipo de narrativa (secular e religiosa $-\mathrm{S}$ e $\mathrm{R}$, respectivamente), considerando como variáveis externas (e) as justificativas dos próprios julgamentos (religioso-metafísica e secular-biológica por cada um dos quatro grupos de perguntas, Meta. e Bio., respectivamente) e as duas faixas etária (6-8 anos e 10-12 anos). O coeficiente de alienação de 0,13 é satisfatório, indicando uma boa representação espacial dos pontos.

A análise da distribuição destes pontos no espaço permite identificar regiões de contiguidades onde informações semelhantes se agrupam. Estas regiões, por sua vez, indicam relações internas dos dados, como também a forma de partição destes espaços pode sugerir hierarquias e relações entre os mesmos. Pode-se observar na 

em Crianças.

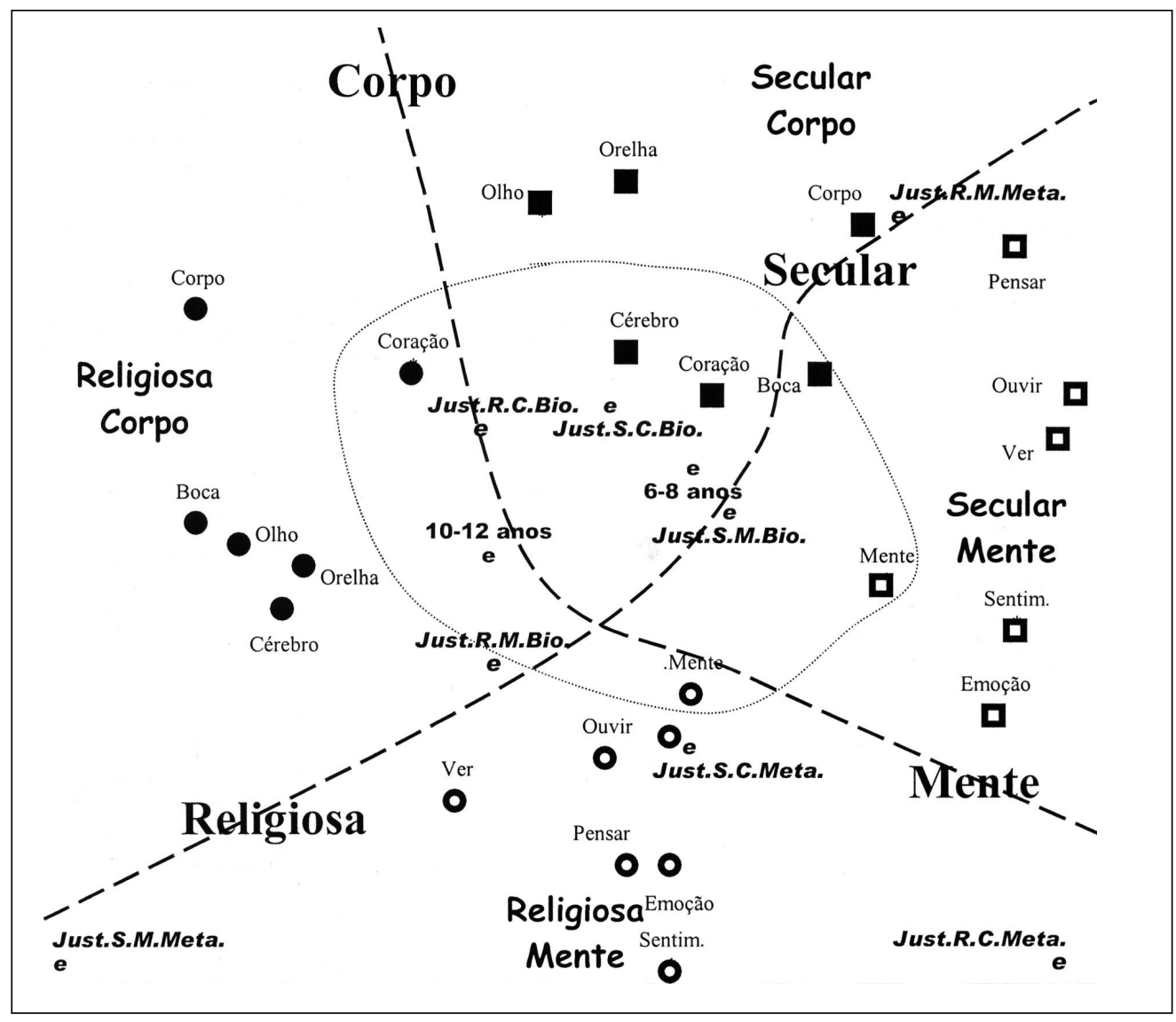

Figura 3. Análise SSA dos 24 julgamentos (0 "funciona", 1 "não funciona") quanto ao funcionamento dos processos Mentais (M) e Corporais (C) em função do tipo de Narrativa (Secular e Religiosa - S e R, respectivamente) considerando como variáveis externas (e) as justificativas dos próprios julgamentos (Metafísica e Biológica por cada um dos quatro grupos de perguntas, Meta. e Bio., respectivamente) e as duas faixas etária (6-8 anos e 10-12 anos)

Nota. Solução Tridimensional, Coordenada 1x2; Coeficiente de Alienação 0,13.

Legenda:

Secular Mente

Secular corpo

Religiosa Corpo

Religiosa Mente

projeção que a variável conteúdo, caracterizada pelos julgamentos das crianças, divide-se em duas regiões de acordo com as duas condições narrativas (secular e religiosa) e processo (corpo e mente). Esta divisão é evidente a partir da presença de duas diagonais ortogonais que dividem claramente o espaço que contém cada condição. Existe uma região no lado esquerdo e inferior que agrega todas as questões seculares, em oposição à região do lado direito superior que abriga as questões religiosas. Outra diagonal perpendicular à primeira divide os julgamentos em função do tipo de processo, em que aqueles relativos à mente localizam-se no lado inferior direito da projeção, e corpo no lado esquerdo superior.

As quatro justificativas secular-biológicas localizamse na região central da projeção, cada uma espacialmente mais próxima ao grupo de julgamentos que lhe são correspondentes, indicando, desta forma, uma congruência entre julgamentos e justificativas. As justificativas religioso-metafísicas, pelo fato de terem sido construídas em direção oposta aos julgamentos, encontram-se loca- lizadas espacialmente distantes e em oposição aos julgamentos correspondentes, indicando também uma coerência entre julgamentos e justificativas.

As duas variáveis externas correspondentes às duas faixas etárias localizam-se na região central próximas entre si, indicando uma similaridade em seus julgamentos com as variáveis conteúdo. A existência de uma região central indica que os processos nesta posição possuem maior correlação com todos os outros. Podemos notar que o não funcionamento do coração e do cérebro possui uma maior correlação com a ideia de não funcionamento das funções corporais independentemente da orientação da narrativa. Do mesmo modo, o não funcionamento da mente possui maior correlação com todas as outras funções da mente. Interessante notar também que a posição periférica das funções emoção e sentimento reforçam a oposição ao julgamento de não funcionamento. A noção da continuação de funcionamento do pensar, das emoções e sentimentos demonstra também uma maior correlação com julgamentos das crianças pequenas. 
Finalmente podemos dizer que a estrutura de regiões dos dados conforme se apresentam na projeção dos mínimos espaços, mostram a existência de regiões de contiguidades que apresentam claramente a correlação entre as justificativas secular-biológicas para o não funcionamento das funções do corpo e as justificativas religiosometafísicas em oposição justificando o funcionamento das funções da mente, principalmente ligadas à emoção.

\section{Análise Comparativa dos Julgamentos das Crianças Recifenses e Espanholas}

Tendo como objetivo verificar as semelhanças e/ou diferenças entre crianças recifenses (no Brasil) e crianças madrilenas (na Espanha), Harris e Gimenez (2005) disponibilizaram seus dados com vista de discutir os resultados $^{2}$. Realizou-se uma ANOVA mista com as crianças mais jovens, comparando País (Brasil e Espanha) $\mathrm{x}$ Narrativa $x$ Tipo de processo. Os Resultados indicaram não haver diferenças significativas entre as crianças de ambos os países para Secular-corpo $F(1,67)=0,043$; $p=0,837$, Religiosa-corpo $F(1,67)=0,113 ; p=0,738$, Secular-mente $F(1,67)=0,213 ; p=0,646$ e Religiosamente $F(1,67) 1,85 ; p=0,177$.

Em seguida, uma ANOVA mista com as crianças mais velhas comparando País (Brasil e Espanha) x Narrativa $\mathrm{x}$ Tipo de processo foi realizada. Os resultados demonstraram não haver diferenças significativas entre as crianças mais velhas de ambos os países para Secular-corpo $F(1,68)=1,620 ; p=0,207$. No entanto, evidenciou-se diferenças significativas para Religiosa-corpo $F(1,68)$ $=7,842 ; p=0,007$, Secular-mente $F(1,68)=4,504$; $p=0,037$ e Religiosa-mente $F(1,68)=24,855 ; p=0,000$.

A análise acima indicou não haver diferenças significativas entre crianças mais jovens de ambas as amostras. No entanto, as crianças mais velhas responderam de maneira diferente á questões sobre o funcionamento da mente e do corpo em um contexto narrativo religioso, e sobre o funcionamento da mente em um contexto narrativo secular. Assim, as crianças espanholas mais velhas apresentaram um maior numero de respostas de natureza metafísico-religiosa quando comparadas ás crianças recifenses.

\section{Discussão}

Foram indicadas algumas questões, suscitadas pela reflexão teórica, as quais a presente investigação se propõe a responder através dos resultados obtidos. A primeira buscava verificar quando concepções religiosometafísicas e secular-biológicas surgem no desenvolvimento conceitual da morte. Tomando-se por base os

\footnotetext{
${ }^{2}$ Harris e Gimenez (2005) entrevistaram 48 crianças, divididas em dois grupos. Vinte e quatro com idade média de 7 anos e 5 meses e 24 com idade média de 11 anos e 4 meses. As crianças eram de uma escola pública na cidade de Madrid (Espanha) provenientes de famílias de classe media e classe media alta.
}

estudos apresentados, a hipótese inicial era de que crianças mais jovens apresentariam uma concepção mais secular-biológica da morte, enquanto que crianças mais velhas começariam a incorporar elementos religiosos e/ ou metafísicos em seu entendimento da morte.

Os dados obtidos indicam que as crianças entrevistadas apresentaram um único padrão de resposta, não havendo qualquer diferença significativa no que diz respeito à variável idade. De uma maneira geral, os participantes emitiram mais respostas de cunho secularbiológico. Evidenciando apenas uma leve tendência não significativa nas crianças mais velhas a emitirem mais respostas de cunho metafísico-religiosas. Este resultado se fez presente tanto na análise dos julgamentos (funciona e não funciona) quanto nas justificativas (secularbiológicas e religioso-metafísicas).

A segunda questão proposta foi comparar os dados obtidos com as crianças recifenses e espanholas (Harris \& Gimenez, 2005). Os resultados indicam que o padrão de resposta das mais jovens é similar, sem diferenças significativas. No entanto, observam-se algumas diferenças significativas ao comparar os dados obtidos com as crianças mais velhas, onde as espanholas apresentam um maior número de respostas metafísicas quando comparadas às crianças brasileiras.

Os dados obtidos indicam primeiramente que as crianças, de fato, fazem uso de ambas as perspectivas (secular-biológica e religioso-metafísica) ao buscar entender a morte, podendo ser guiadas por conhecimentos do domínio da psicologia e da biologia. O que torna tal explicação mais plausível vem a ser o maior uso de recursos secular-biológicos para explicar o fim do corpo, e um maior uso de recursos religioso-metafísicos para explicar a possível continuação de processos mentais em uma vida após a morte.

Em segundo lugar, observa-se que as crianças espanholas começam a fazer uso de recursos religioso-metafísicos de maneira mais precoce em relação às crianças recifenses. É possível que um entendimento secular-biológico esteja mais ao alcance destas crianças. Em ambos os contextos culturais, elas são expostas na escola a ensinamentos sobre a biologia do corpo. Fomentando assim um entendimento melhor acerca dos processos fisiológicos que dão sustentação à vida e como estes se relacionam com o advento da morte. Existe um grande número de estudos comprovando que o desenvolvimento de um entendimento biológico da morte se dá de maneira constante em diversas culturas (Brent et al., 1996; Wenestram \& Wass, 1987), inclusive em crianças brasileiras (Nunes et al., 1998; Torres, 1979).

Por outro lado, um entendimento religioso-metafísico da morte pode ser recrutado de maneira diversa, dependendo da cultura em que a criança está inserida, o que nos parece explicar as diferenças observadas entre ambas as amostras. Sugere-se que estudos futuros explorem como diferentes culturas recrutam tal entendimento da morte e como isto varia ao longo do desenvolvimento 
infantil, controlando variáveis como: religião da família, tipo de escola (religiosa ou secular) e frequência das crianças em instituições religiosas.

Dando continuidade à discussão, a terceira questão que propomos responder busca verificar se crianças consideram concepções religioso-metafísicas e secular-biológicas como sendo compatíveis ou incompatíveis entre si. A crença na incompatibilidade as levaria a adotar uma única perspectiva da morte, e a responderem de maneira consistente ao longo de todas as questões apresentadas. Enquanto que a crença na compatibilidade as levaria a adotar um padrão de respostas para algumas circunstâncias e outro padrão para outras.

Os resultados apontam que o padrão das respostas varia marcadamente dependendo do tipo de narrativa. Respostas do tipo "não funciona" (de caráter secularbiológico) foram menos frequentes no contexto religioso do que no contexto secular, e em questões sobre a mente do que em questões sobre o corpo. Por outro lado, as respostas do tipo "funciona" (de caráter religioso-metafísico) apareceram mais no contexto religioso do que no contexto secular, e em questões sobre o funcionamento da mente. Este padrão de resposta foi observado em ambos os grupos de idade.

Considera-se então se não se poderia esperar a tentativa de evitar estas aparentes contradições por parte das crianças, nas quais apresentem simultaneamente concepções secular-biológicas e religiosas da morte. Partese assim para refletir sobre algumas possíveis explicações que levam crianças a emitirem este tipo de padrão de reposta. Primeiramente pode ser possível que elas não percebam tal contradição, portanto não as incomoda. De acordo com Ruffman (1999), crianças pequenas frequentemente falham em identificar contradições, incluindo incoerências lógicas claras. No entanto as crianças melhoram sua capacidade em reconhecê-las, sendo improvável que uma criança de 11 anos não as perceba, muito pelo contrário, nesta idade elas são muito perspicazes em detectar contradições (Harris, Kruithof, Meerum Tergoth, \& Visser, 1981; Markman, 1979). Assim sendo, esta suposição não fornece uma explicação para os dados obtidos.

Outra possibilidade é a de que as crianças reconhecem esta incompatibilidade, mas escolhem atribuir um grupo de questões (sobre a mente) como sendo de ordem religioso-metafísica e outro grupo de questões (sobre o corpo) como sendo secular-biológicas. Esta forma de conceber a morte incorpora ambas as condições, eliminando o efeito anteriormente contraditório e reconciliando o que parecia incompatível.

Ao se observar justificativas emitidas pelas crianças, fica evidente uma construção lógica permitindo que ambas as perspectivas, tanto secular-biológicas quanto religioso-metafísicas viessem à tona. Quando uma criança diz que o corpo morreu e foi enterrado, e consequentemente o coração não bate, assim como outras funções corporais, mas que suas funções mentais ainda se per- petuam em uma vida espiritual, especialmente a de pensar, ouvir e ter emoções, (pois na vida espiritual tais funções ainda "funcionam", pois a pessoa precisa "ouvir e conversar com Deus e com os anjos"), fica evidente a ausência de tensão nesta construção lógica.

As respostas das crianças podem estar sendo guiadas e limitadas por domínios específicos do saber, em especial o domínio da biologia e da psicologia. Desta maneira, ao construir uma teoria acerca da morte, elas podem adotar: (a) uma perspectiva biológica/secular, fazendo uso de um mecanismo explanatório-intuitivo do domínio da biologia, em que a morte leva a cessação de todas as funções corporais; (b) uma perspectiva religioso-metafísica, fazendo uso de um mecanismo explanatório-intuitivo do domínio da psicologia, em que a morte não impõe um fim às funções mentais.

Por último, procurou-se explorar a consistência das respostas analisando perspectivas diferentes, mas, no entanto, relacionadas. Por exemplo, se as crianças concebem uma pessoa como um inteiro indivisível, e a seguir perguntamos sobre processos corporais (se os olhos ou cérebro ainda funcionam), ou sobre processos mentais concomitantes (por exemplo, se a visão ou a mente funcionam), devem, portanto, produzirem respostas consistentes - por exemplo, afirmando que a visão e função dos olhos funcionam. Caso as crianças sejam suscetíveis a pensamentos dualísticos - interpretando processos mentais como distintos dos processos corporais - ofereceriam padrões de respostas diferentes para cada processo.

Os dados analisados apontam para a segunda opção, na qual se observa que crianças de ambas as idades emitiram respostas afirmando que apesar de se ter perdido os sinais vitais, (processos corporais) o processo mental continua ativo. Ratificando assim um pensamento dualístico, no qual é evidenciado que em geral elas interpretaram processos mentais como separados e independentes dos processos corporais. Este resultado, mais uma vez, aponta para a possibilidade de mecanismos explanatóriointuitivos de domínios distintos serem recrutados pelas crianças para elaborar um conceito de morte.

\section{Considerações Finais}

A "teoria da teoria" busca explicar os mecanismos cognitivos pelos quais crianças fazem uso ao compreender o mundo, sendo estes de natureza explanatório-intuitivas. Embasando-nos nestes pressupostos teóricos, buscou-se explorar os resultados obtidos, trazendo à tona possíveis processos cognitivos que podem estar guiando a construção de um conceito de morte em crianças.

Os dados obtidos apontam que crianças fazem uso de mecanismos explanatório-intuitivos do domínio da psicologia e da biologia ao elaborar uma compreensão da morte. Também se observou que construções oriundas do domínio da psicologia surgem mais tarde no desenvolvimento, e que variam dependendo do contexto cultural na qual a criança está inserida. Estes resultados 
assinalam que primeiramente existem mecanismos cognitivos básicos guiando o processo de construção de um conhecimento de morte, mas que o trajeto de construção é influenciado por uma cultura na qual a criança está inserida. Esta cultura provê noções de biologia e religiosas e/ou metafísicas sobre a morte. As noções de biologia se dão de duas formas. Primeiro, uma exposição mais estruturada a ensinamentos acerca do funcionamento do corpo em um contexto escolar. Segundo, uma exposição menos estruturada, via experiências empíricas que crianças possam vir a ter com a morte de insetos e/ ou animais de estimação. Esta exposição informal pode levá-las a pensar sobre a morte, motivando-as a questionarem pessoas a sua volta, fomentando um entendimento acerca da biologia da morte assim como também uma curiosidade acerca de uma possível vida após a morte.

As noções religiosas e/ou metafísicas acerca de uma continuação após a morte podem ser transmitidas de maneira diversa. Primeiramente, através de ensinamentos religiosos passados pela família, comunidade e/ou igreja. Segundo, pela exposição a filmes e programas de televisão que trazem elementos metafísicos sobre a morte, como fantasmas, espíritos e reencarnação. Diante das diversas formas de exposição a informações pertinentes a um entendimento da morte, futuras investigações devem focar em destrinchar o efeito de variáveis culturais específicas neste processo de construção, buscando elucidar o que torna noções de biologia mais recrutáveis desde cedo, e o que torna noções religiosas e/ ou metafísicas mais suscetíveis a variações culturais.

\section{Referências}

Astuti, R., \& Harris, P. L. (2008). Understanding mortality and the life of the ancestors in rural Madagascar. Cognitive Science, 32, 713-740.

Bering, J. M. (2006). The Folk Psychology of souls. Behavioral and Brain Sciences, 29, 453-498.

Brent, S. B., Speece, M. W., Lin, C., Dong, Q., \& Yang, C. (1996). The development of the concept of death among Chinese and U.S. children 3-17 years of age: From binary to "fuzzy" concepts? OMEGA: The Journal of Death and Dying, 33, 67-83.

Cohen, E. H., \& Amar, R. (1999). External variables as points in SSA: A comparison with the unfolding techniques. In R. M. Schweitzer, D. Hänzi, B. Jann, E. Peier-Kläntschi, \& H. J. Schweizer-Meyer (Eds.), Facet theory: Design and analysis (pp. 259-279). Bern, Switzerland: Facet Theory Association.

Cohen, E. H., \& Amar, R. (2002). External variables as points in smallest space analysis: A theoretical, mathematical and computer-based contribution. Bulletin de Methodologie Sociologique, 75, 40-56.

Guttman, L. (1968). A general nonmetric technique for finding the smallest co-ordinate space for a configuration. Psychometrika, 3, 469-506.

Harris, P. L., \& Giménez, M. (2005). Children's acceptance of conflicting testimony: The case of death. Journal of Cognition and Culture (Belfast), 5(1/2), 143-164.
Harris, P. L., Kruithof, A., Meerum Tergoth, M., \& Visser, T. (1981). Children's detection and awareness of textual anomaly. Journal of Experimental Child Psychology, 31, 212-230.

Inagaki, K., \& Hatano, G. (2002). Young children's naïve thinking about the biological world. New York: Psychology Press.

Markman, E. (1979). Realizing that you don't understand: Elementary school children's awareness of inconsistencies. Child Development, 50, 643-655.

Miller, H. P. (2002). Theories of Developmental Psychology. New York: Worth.

Nunes, D. C., Carraro L., De Jou, G. I. U., \& Sperb, T. M. (1998). As crianças e o conceito de morte. Psicologia: Reflexão e Crítica, 11(3), 579-590.

Roazzi, A. (1995). Categorização, formação de conceitos e processos de construção de mundo: Procedimento de classificações múltiplas para o estudo de sistemas conceituais e sua forma de análise através de métodos de análise multidimensionais. Cadernos de Psicologia, 1, 1-27.

Roazzi, A., \& Dias, M. G. B. B. (2001). Teoria das facetas e avaliação na pesquisa social transcultural: Explorações no estudo do juízo moral. In Conselho Regional de Psicologia $13^{\mathrm{a}}$ Região $\mathrm{PB} / \mathrm{RN}$ (Ed.), A diversidade da avaliação psicológica: Considerações teóricas e práticas (pp. 157-190). João Pessoa, PB: Idéia.

Ruffman, T. (1999). Children's understanding of logical inconsistency. Child Development, 70, 872-886.

Torres, W. C. (1979). O conceito de morte na criança. Arquivos Brasileiros de Psicologia, 31, 9-34.

Young, F. W. (1987). Multidimensional scaling: History, theory and applications. Hillsdale, NJ: Erlbaum.

Wellman, H. M. (1990). The child's theory of mind. Cambridge, MA: The MIT press.

Wellman, H. M., \& Johnson C. N. (2008). Developing dualism: From intuitive understanding to transcendental ideas. In A. Antonietti, A. Corradini, \& E. J. Lowe (Eds.), Psychophysical dualism today: An interdisciplinary approach (pp. 50). Lanham, MD: Lexington Books.

Wenestram, C. G., \& Wass, H. (1987). Swedish and U.S. children's thinking about death: A qualitative study and crosscultural comparison. Death Studies, 11(2), 99-121.
Recebido: 01/02/2009

$1^{a}$ revisão: $27 / 04 / 2009$

$2^{a}$ revisão: 01/06/2009

$3^{a}$ revisão: 07/07/2009

Aceite final: 07/07/2009 
Roazzi, M. M., Dias, M. G. B. B. \& Roazzi, A. (2010). Mais ou Menos Morto: Explorações sobre a Formação do Conceito de Morte em Crianças.

\section{ANEXO A}

\section{Exemplo de Questionário}

Narrativa Religiosa

Quando a avó de Clara Nina estava bem velhinha ela ficou muito doente. Foram feitos exames em um hospital para ver se conseguiam ajudá-la, mas ela estava velhinha demais e não puderam curá-la. $O$ padre veio falar com Clara Nina sobre o que tinha acontecido a sua avó. Disse a Clara Nina: 'Sua avó era muito doente. Não houve nada que os médicos puderam fazer. Sua avó está com Deus agora.' Agora que a avó de Clara Nina está com Deus...

\begin{tabular}{ll}
\hline Grupo questões Corpo & Grupo questões Mente \\
\hline Agora que a avó de Clara Nina está com Deus.. & Agora que a avó de Clara Nina está com Deus.. \\
...seus olhos não funcionam mais? & ...parou de ver? \\
...suas orelhas não funcionam mais? & ..pparou de ouvir? \\
...seu cérebro não funciona mais? & ...parou de pensar? \\
...su coração boca funciona? & ...pode ter sentimentos? \\
...seu corpo funciona? & ...pode ter emoções? \\
\hline Por que o corpo dele ainda está funcionando & ...sua mente funciona? \\
(não funciona mais)? & Por que a mente dele ainda está funcionando \\
\hline
\end{tabular}

Narrativa Secular

Quando o avô de Alfredo estava velhinho ele ficou doente. Foram feitos vários exames em um hospital para ver se conseguiam curá-lo, mas ele já estava velho demais e não adiantou. $O$ doutor veio falar com Alfredo sobre o que tinha acontecido a seu avô: 'Seu avô estava muito doente. Não teve nada que os médicos pudessem fazer. Seu avô morreu'.

\begin{tabular}{ll}
\hline Grupo questões Corpo & Grupo questões Mente \\
\hline Agora que o avô do Alfredo morreu... & Agora que o avô do Alfredo morreu... \\
... seus olhos não funcionam mais? & $\ldots$ parou de ver? \\
... suas orelhas não funcionam mais? & $\ldots$ parou de ouvir? \\
... seu cérebro não funciona mais? & $\ldots$ parou de pensar $?$ \\
... sua boração funciona? & $\ldots$ pode ter sentimentos? \\
... seu corpo funciona? & $\ldots$ pode ter emoções $?$ \\
\hline Por que o corpo dele ainda está funcionando & $\ldots$ sua mente funciona? \\
(não funciona mais)? & Por que a mente dele ainda está funcionando \\
\hline
\end{tabular}

